\title{
Chapter 6 \\ Global Citizenship Through the Lens of Indigenous Pedagogies in Australia and New Zealand. A Comparative Perspective
}

\author{
Nigel Bagnall and Sarah Jane Moore
}

\begin{abstract}
This chapter looks at the need for inclusive teaching especially for minority groups. It draws upon the experiences of two Pacific Nation's with different histories and cultural traditions: The Maori in New Zealand and the Aboriginal and Torres Strait Islanders' in Australia. Drawing on over 40 years teaching and researching in national schools, international schools and universities, we show how complex the global classroom has become. In particular, we look at the way education in New Zealand has much to teach Indigenous members of the global classroom. We raise the question of the Aboriginal voice in current Australian educational provision. How to be heard and what more needs to be done to include all the strands of Australian inhabitants, not just the most recent arrivals.
\end{abstract}

Keywords Global citizenship · Education and belonging · Critical multiculturalism · Indigenous education · Indigenous research $\cdot$ Reconciliation

\section{Introduction: Don't forget me cuz!}

Critical multiculturalism challenges unequal power relations in education (May and Sleeter 2010) and embraces new ways and old ways (Moore and Birrell 2011) of thinking, learning and knowing. This chapter looks at the need for inclusive

\footnotetext{
N. Bagnall ( $\square)$

The University of Sydney, Sydney, Australia

e-mail: nigel.bagnall@ sydney.edu.au

S. J. Moore

University of NSW Sydney, Kensington, Australia

e-mail: sarahjane.moore@unsw.edu.au 
pedagogies and research strategies that focus on minority groups. It examines the politics of forgetting and embeds the importance of feeding, celebrating and listening to the living memories of Maori, Pacific Islander and Aboriginal and Torres Strait Islander cultures through arts-based methods. It models projects that present land, or Country ${ }^{1}$ as a vital learning partner that nourishes understandings between colleagues and communities of practice. It describes case histories where reforms and changes were enacted and Aboriginal knowledge recognized. Instances are described where Aboriginal Elders, academics and researchers were given the opportunity to lead learning and the chapter tracks the impact of these innovations on tertiary learning. The chapter stories moments where imaginative and creative pedagogies are explored and gives evidence of the potential of these modes to drive change. It draws upon the experiences of two Pacific nations with different histories and cultural traditions: The Maori in Aotearoa New Zealand and Aboriginal and Torres Strait Islanders in Australia. It stories pedagogies that model dynamic Oceanic dialogues that create inclusive and multi-dimensional global identities. It affirms the importance of the inclusion of creative identities in multicultural conversations. It presents the power of story, images, and imaginative work to disrupt power relationships that minimize the cultural capital of First Peoples. It examines the significance of projects, ideas and collaborations in Higher Education contexts where Indigenous Oceanic identities are at the nerve center driving change.

Drawing on over 40 years teaching and researching in national schools, international schools and Universities, Bagnall shows how complex the global classroom has become. In particular, he looks at the way New Zealand education has much to teach many Indigenous members of the global classroom. The chapter seeds the importance of the creative arts in facilitating and transmitting global citizenship and affirms the importance of the story in establishing socially just narratives of global identity.

The focus on arts-based innovation is growing globally. The recently published text Arts-based methods and organizational learning; higher education around the world mapped and explored a variety of arts-based methods (ABM) and contexts (Chemi and Du 2018).

Making use of her creative arts research background, Moore gives examples of how Aboriginal and Torres Strait Islander voices, stories and histories have been heard in current Australian educational provision through the description of case study projects at the University of Sydney and the University of Guam. She examines ways in which Oceanic voices have been prioritized and embedded through creative research projects and suggests that similar models may achieve success in global contexts. She examines inclusion strategies that enable all the strands of Australian inhabitants to be embraced. She gives evidence of transformational moments in projects and qualitative research that over a period of a decade have had cumulative effects in democratizing the learning and teaching space and describes instances where practical, symbolic and personal Reconcilations have been achieved.

\footnotetext{
${ }^{1}$ The Aboriginal meaning of 'Country' includes the landscape, waters, air, trees, rocks, plants, animals, foods, medicines, minerals, stories, ...
} 


\section{Critical Multiculturalism and Reconciliation Frameworks}

The first publicly recorded use of the term 'Reconciliation' to describe reconciling Australia's Aboriginal Peoples within a recently settled white Australian context occurred in 1983 in a speech by Clyde Holding, the first Minister for Aboriginal Affairs in the Hawke Government (Ahluwalia et al. 2012). Whilst the term was used in 1983, Linda Burney's 2000 definition is preferred for this chapter.

Broadly speaking, Reconciliation is about recognition, rights and reform. It is recognition of Aboriginal and Torres Strait Islander Peoples as the original People of this land, and it is recognizing the Aboriginal history of this land, both the long Aboriginal history before the invasion, and the shared history since. Reconciliation is recognizing the rights that flow from being the first Peoples, as well as our rights as Australian citizens in common with all other citizens. It is about reforming systems to address the disadvantages suffered by Aboriginal Peoples and, as I have said, it is about changing the frame of reference of all Australians to include Aboriginal Australian (Burney 2000, p. 66).

This definition was chosen because it articulates concepts of recognition, rights and reform for Aboriginal Peoples. It conveys a sense of the history of Aboriginal Peoples and offers the possibility of a collective history for all Australian Peoples. It acknowledges the significance of the land to Aboriginal Peoples and flags the possibility of the acknowledgement of universal rights, but also the recognition of special rights for Aboriginal and Torres Strait Islander Peoples. The use of terms such as 'reform', 'recognition' and 'change' in the definition makes possible the reimagining of community (Ahluwalia et al. 2012) in a practical sense. Indeed, this definition embraces the cultural politics of Reconciliation and presents its possibilities as nation building and life changing. The use of the term 'suffering' in this context acknowledges the history of hurt for Aboriginal Peoples in Australia. Reconciliation is thus conceptualized in this writing as a healing practice (Ahluwalia et al. 2012) made possible through inclusion, reform and recognition. This chapter gives evidence of inclusion, reform and recognition that occurred over a 10-year period at the University of Sydney and presents examples of global identities within communities of practice that have included Indigenous voices, perspectives and players.

\section{Background Story}

Nigel Bagnall and Sarah Jane Moore met in 2007 and have worked collaboratively from that time, both as mentor and mentee, colleagues and friends. Bagnall and Moore worked closely on the Embedding Diversity research project at the University of Sydney from 2007 to 2010 where academics were encouraged to address Aboriginal and Torres Strait Islander perspectives within their teaching, learning and research practices;

The outcome of this project was a commitment to change and advocacy for cultural competence to embedding stronger and more informed Aboriginal education, Aboriginal Studies 
Units of Study (subjects), and perspectives in teacher education curriculum (Mooney and Moore 2013, p. 302).

The tools for change were simple; Moore was employed to initiate conversations with members of the Faculty of Education and Social Work ${ }^{2}$ and was asked to create opportunities that focused on social justice for minority students. Moore aimed to map how staff members were embedding Aboriginal and Torres Strait Islander perspectives within their current work and in turn identify opportunities for change. During a 6-month period, Moore interviewed over 40 education-focused academics face to face. In all of the interviews conducted, the academics communicated that they recognized the need for change and showed willingness to shift their approaches. Moore trialed a number of arts-based methods in assisting others to embody critical multiculturalism and reform, recognize and change including a "Connecting to Country" visit with Ainwan-Gamilaroi-Darnginjung Aboriginal elder Oomera Edwards.

\section{Transformations; Connecting to Country and Elder-Led Learning}

The visit to Darninjung Country in New South Wales Australia was planned following requests from faculty members for more information about Aboriginal and Torres Strait Islander cultures and knowledge. Through consultation with faculty members, it emerged that people were keen to begin engaging with Aboriginal and Torres Strait Islander perspectives in their work. One participant articulated her reason for attending the day: "I want to better understand appropriate communication approaches when working with Indigenous students". Another stated: "I want to learn about Indigenous ways of knowing in the hope that it will enhance my understanding and hence my teachings". This visit to Country offered participants the opportunity to learn about Indigenous cultures, gain insight into ways to connect to Country, to learn about kinship systems and to better understand the ways in which Indigenous students experience the school system. One participant stated that the trip provided, "a unique opportunity to talk to an Indigenous elder sharing her understanding and supporting ours". Throughout the learning, Oomera Edwards maintained, "you can't teach Country in a classroom", and the full day experience enabled participants to walk on, listen to and learn about Country from an Aboriginal perspective.

Faculty staff self-selected to spend a day with Oomera in Ourimbah in New South Wales, Australia in order to improve their understanding of Aboriginal cultures and assist in democratizing the ways in which they taught Aboriginal students and engaged with Aboriginal learning content. The connecting to Country experiences acknowledged the importance of nature-based, land led-learning. The land

\footnotetext{
${ }^{2}$ The Faculty is now a School within the Faculty of Arts and Social Science.
} 
became the learning partner on this day and the focus and power relationships were shifted. Experts became novices, speakers became listeners and writers became observers. Without lap-tops, mobile phones or pens and lined paper, which so often become ways of thinking, recording and mapping learning for individuals, the group was asked to listen to stories and act as a collective, to move as a group, to care for each other and to think of the land as a living entity with knowledge to impart. They were asked to notice and listen to birds, to observe insects and note the possibility of Country to provide nourishment and support. They were encouraged to journey imaginatively and close their eyes and listen for sounds of the bush, to dance, stamp and sing. The group was directed to sit on large sand stones and learn a simple song using words from a local Indigenous language. The language was foreign to the group, the words new to them and previously unspoken. They were now outsiders. No longer encountering learning in accustomed ways, the experience of flipping the classroom and engaging with Country as a teacher was transformational.

The Embedding Diversity research program fostered critical multiculturalism that acknowledged that Aboriginal and Torres Strait Islander Peoples and communities have had and continue to have custodial links to the land. One participant commented: "The day encouraged me to see a different world view and to start the process of developing a link to Country". In this way elder-led programs, projects and land-based learning encounters changed the ways academics recognized Indigenous students and their links to land by beginning to develop their own dialogues with Country. The program acknowledged the need to reform and recognized that Aboriginal and Torres Strait Islander Peoples have been and continue to be collectively discriminated against. An academic who participated in the elder-led learning stated in his feedback: "Reaching out and consequently assisting disadvantaged and displaced people is not easy and one can easily offend (which would be counterproductive) but Oomera has a sincere way of bridging those gaps and has passed that on effectively to me".

By placing an Aboriginal elder as an expert in a place of learning where her knowledge was valued and celebrated, the academics present imagined a global identity that moved beyond an Anglocentric perspective. It refocused their thinking and challenged their ways of knowing. One participant reflected;

I gained an awareness of how an Indigenous person thinks and feels about their Country and to learn that not all Country is the same and that I have many of the same feelings and experiences but that I may have just forgotten them.

Learning in this way has the ability to enrich the capacity of individuals and groups to un-know. Through the process of un-knowing, new possibilities of global identities that support Indigenous knowledge were enacted. One participant reflected;

The leader of the workshop was very supportive and had a deep knowledge of her topic. The day-long experience was designed to build our understanding in both head and body. I came away with a sense of connection that I did not have before. But I know it is only the beginning of what I need to learn. 
A community of practice that is encouraged to not only reflect on but, connect to and listen to Country is a global community that enables new power relationships to be forged. The long-term shifts in thinking, knowing and being that the Embedding Diversity Connecting to Country program encouraged, were described through the words of a participant who stated that;

It is almost a week after the day and I am still reflecting on the experience. I think that the main benefit is an introduction to a different way of approaching knowledge and the 'world' around us.

The Embedding Diversity project also involved a research field trip to Aotearoa New Zealand in 2007 that seeded and modeled ways of working to prioritize the listening to and storying of Indigenous knowledge, through song, story and oral transmission. Sharon Galleguillos, the highly experienced lecturer in Aboriginal Education, accompanied Moore and Bagnall for this 2-week visit. In 1976, Sharon was one of only two Indigenous graduates of the Certificate of Teaching program at Kedron Park Teachers' College, Brisbane. Drawing on her considerable experience of Indigenous education, as a practitioner and policy developer, she provided Indigenous leadership to the research program that involved deep insights into the need for grassroots democratization and access to education for Indigenous tertiary students. The team of Galleguillos, Moore and Bagnall visited a number of educational provision sites and were invited to speak to Maori and Pasifika community members about the reforms and changes necessary to achieve social justice for First Peoples students.

During the negotiations ahead of the visit, Moore was informed that her research conversations would only be supported if they were Indigenous-led. Sanga explored the notion of learning from Indigenous leadership (Sanga 2017) and in this way, the research conversations at the University of Auckland were begun ceremonially as the research party was welcomed on to Faculty Marae through singing and story. Maori was spoken, sung and was the preferred language. The cultural protocols for the research conversations firmly in place, The University of Auckland gave time to the research through a day of sharing session where Maori, Pasifika ${ }^{3}$ and Pakeha ${ }^{4}$ staff shared their personal stories around a circular table. During the research conversations, Education and Social work staff spoke reflectively on how they were transforming their own practices and responding to the need to acknowledge, embed and celebrate Maori histories, voices and funds of knowledge (Moll et al. 1992; Vélez-Ibáñez and Greenberg 1992) in their work. They spoke of past and present work and their plans for the future. As a senior and respected Indigenous educator, Galleguillos took leadership in these stories and sharings and gave her perspectives on the discussions. Other less senior and non-Indigenous colleagues participated through listening. Narrative styles and story sharing were adopted as the mode in which the research conversations occurred.

\footnotetext{
3 "Pasifika" refers to people living in New Zealand who have migrated from the Pacific Islands or who identify with the Pacific Islands because of ancestry or heritage.

${ }^{4}$ Pakeha is a Maori-language term for New Zealanders of European descent.
} 
At the time Moore wondered if critical multicultural dialogues embraced more aural and oral traditions in Australia, would they lead to deeper conversations. She questioned Galleguillos and Bagnall at the time whether research conversations in Australia were to more often embrace a yarning session or story circle, or talanoa where time was offered to listen to Aboriginal perspectives from local custodians, would Indigenous leadership models then be modeled and embedded in global research conversations in more secure and permanent ways. The research visits to Aotearoa New Zealand culminated in a day-long workshop for the faculty back at the University of Sydney. Galleguillos, Moore and Bagnall reported on their learning and these initiatives provided the team with opportunities to story, discuss, and share their learning through images and discussions. Informal feedback on the day gave evidence that staff found it useful and enjoyed the fact that the learning was enacted and not presented as a report. During this day of sharing, Aboriginal artists, storytellers, musicians and poets were employed to give performances and presentations. In this way, the importance of the sharing of creative pedagogies was affirmed.

Alongside the interviews, Connecting to Country Days and the International research program, the Embedding Diversity project involved more traditional outputs. In 2008, Moore co-wrote a journal article with Associate Professor Alyson Simpson that mapped the learning from the project. Moore was struck by Simpson's honesty and critical lens when she wrote:

\footnotetext{
Listening to an Elder speak of connection to Country and the principles of community that were related to the physical survival of a group of individuals and the maintenance of complex social and spiritual relationships, I realized how most of the teaching I was involved in was decontextualized and individualized. Even though the illustrated principles of learning espouse connection to authentic contexts the knowledge taught usually relates to advancement through artificial ranks of measurement in school systems. Learning is often competitive, designed to advance the individual rather than non-competitive, designed to support the community (Simpson and Moore 2008 p. 8).
}

Writing with Simpson encouraged Moore to reflect on the importance of reforming the ways in which Indigenous knowledge was transmitted. Rather than re-enacting text-based iterations of knowledge, where complex theories were formulated, Moore explored the notion of writing creatively for the journal, including photographs and art works and writing in ways that improved access to and democratized the ways in which information was shared.

\section{What Does Cultural Democracy Look Like from an Indigenous Perspective?}

Cultural democracy from an Indigenous perspective means that Aboriginal and Torres Strait Islander are given the opportunity to work, and develop competence with their non-Aboriginal colleagues.

The Embedding Diversity project allowed a reflective and process-based deep learning to occur which enabled practical and meaningful Reconciliation to transpire between 
Aboriginal and non-Aboriginal staff. Within the Faculty of Education and Social Work, staff collaborated with, listened to, and were taught by Aboriginal Peoples in a range of contexts. Through this partnership, training, engagement, and conversations were had that shifted perspectives and changed thinking (Mooney and Moore 2013).

As an integral part of the Embedding Diversity Project, in 2008 Lynette Riley, a Wiradjuri and Gamilaroi woman from Dubbo and Moree gave an inspirational and groundbreaking workshop, where she employed role-play and drama-based activities to present her teaching. Riley was at the time a Senior Lecturer at the University of Sydney and she presented her interactive kinship workshop to 80 predominantly non-Aboriginal staff. The interactive face-to-face presentation was first developed in 1987 by Riley to assist understanding of traditional kinship structures and the impact of colonization. Riley consulted with Aboriginal Peoples widely (Riley et al. 2015) and delivered her learning by dividing the participants into different family groupings. They were invited to group and re-group; exploring the learning space in physical ways and thereby enacting the different relationships, connections and associations that related to the kinship structures that Riley was teaching. Staff feedback from this game-based session was that the workshop was impactful. Bagnall reflected on his own learning from Riley in his words:

The shared experience of playing the kinship game under the leadership of Lynnette Riley, was a very significant part of acknowledging how some aspects of belonging and acceptance can lead to Reconciliation both on a personal and community level. I speak here as a pakeha from New Zealand who has spent more time living out of New Zealand than in. I feel very much like an infant in the ways of Maoridom and enacting and walking through the kinship structures I felt like I had put a significant piece within myself; one that had been missing. A piece of understanding about the ways of being, knowing and thinking of Aboriginal families and clans in Aboriginal nations was found for me. Playing the kinship game and walking through the encounter enabled an understanding that could not be found in a book. Physically embracing the encounter has opened up and created the most important space for future generations of Australian students, teachers and learners at the University of Sydney. Early connections with Country with Oomera Edwards and kinship games with Lynnette Riley are enacted and re-enacted as I continue my work within the School of Arts in 2019, some twelve years later. Today I see a place where all may feel welcome and want to participate in the creation of new knowledge and new ways of being. My own work on global identity and belonging is my Pakeha response to the need to know where I come from and how I am connected to Country, whether that be New Zealand or Australia. Working alongside colleagues and seeing their responses to the activities led by Aboriginal and Torres Strait Islander staff members was one of the most important times in my twenty-five years at the University.

\section{The Importance of the Creative Arts and Sharing Stories in Global Communities}

A Culture and Wisdom Talking Transformation project, delivered by Bagnall and Moore at The University of Sydney in 2017, drew upon the experience gained from the Embedding Diversity project and acknowledged the importance of ongoing 
Reconciliation dialogues and conversations. The creative arts workshops offered networking opportunities where Sydney-based comparative educationalists could meet together in a face-to-face environment and share ideas using creative modes. The workshops allowed participants the opportunity to story how their work embraced Indigenous cultural wisdoms and encouraged each participant to produce a canvas that symbolized their relationship with Aboriginal and Torres Strait Islander knowledge, wisdom, stories and histories. Instead of sharing through reports, PowerPoint slides or through the written word, students, lecturers, researchers and children shared their stories and images through painting.

The workshop participants created an exhibition of visual artworks that were presented to the public at the University of Sydney from September 6 to October 6 . They were able to view their own completed canvas alongside the work of others and to see how their perspectives joined and grew together as a collective. Bagnall and Moore were mindful to avoid enacting a project that re-iterated the individual, competitive approach that Simpson wrote about in 2007. Talking Transformations was designed to support community minded participation, be non-competitive and inclusive. After being exhibited in Sydney, the canvases traveled to Noumea, where they were added to and re-exhibited at the University in New Caledonia during the OCIES $^{5}$ Conference held there. Researchers, students and academics shared and exchanged conversations about their cultural wisdom and interfaced with Indigenous knowledge, creating images that acknowledged their own places of belonging.

Workshop participant Matthew Thomas, Associate Lecturer in Education at the School of Arts reflected to Moore in 2017 that;

The project was wonderful on several levels - it enabled collective discussion in a nonthreatening and relaxed atmosphere, creative expression, and most importantly, an opportunity to pause.... and reflect... on Indigenous histories as they are both lived and told as well as assumed and overlooked.

Remembering, mapping, pausing and reflecting were vital ways in which critical multiculturalism could embrace a new way forward and endorse a fresh global identity. Reform, recognition and change could be enacted and truth telling through images and metaphor were encouraged. Here, researchers were given the opportunity to reflect on their own stances in critical ways and to commit to seek out, check in on and include Aboriginal and Torres Strait Islander perspectives in innovative ways.

Moore extended the creative arts and story sharing global conversations through The Artistic Residency program at The University of Guam in 2016. In her collaborative project with Dr. Dean Olah of the school of Education she developed canvases with pre-service teachers and fine arts students mapping their Indigenous knowledge and stories. The local, Indigenous students in the class, the Chamorro students created canvases that delineated their latte stones. These pillars, topped by a hemispherical stone capital with the flat side facing up were used as building

${ }^{5}$ OCIES is the acronym for the Oceania Comparative and international education society. They held their annual meeting in Noumea in 2017. 
supports by the ancient Chamorro People and are found throughout most of the Mariana Islands. The Chamorro students depicted them and told stories about how important the pillars were to their identity as Indigenous Chamorro Peoples. The students delighted in the sharing of images and stories as a discovery tool. The creative pedagogies enacted through the canvases enabled a collective sense of knowing, being and thinking (Martin 2008) to develop. When Moore and Olah asked what was the most memorable activity in the creative artistic residency a number of students spoke about the activity enabling the class to grow as a collective. One student remarked, "(...) presenting our canvas to the class made me see the different personalities we had in the classroom". Another noted: "It was a great activity for getting to know the people in your class as a simple canvas can reveal so much about a person's values, deep thoughts, and creative mind". The success of the project lay in the depth of the responses made possible through the students sharing images and symbols and then storytelling to each other using the canvases as a prompt. Olah and Moore discussed in their post-research dialogues how the canvases were used as a mirror, both to gaze within and to shine out. One participant commented: "The canvas paintings allow you to see what someone holds as important".

The residency in Guam provided opportunities for Pacific cultural perspectives to be gathered and heard in a global context. The arts-informed research approach gave permission to share and the freedom to explore individual stories, approaches and issues of the participants. The research reformed the way in which students acknowledged themselves as First Peoples and encouraged telling of truths. The creative pedagogies enacted carved out a space for listening to local wisdom and honoring local participants and stories in classrooms and learning spaces. It demonstrated the power of the creative arts to strengthen teacher education by empowering and listening to its Indigenous participants.

\section{Indigenous Truth-Telling and Global Identity}

The importance of "truth-telling", in Australian Aboriginal and Torres Strait Islander perspectives, cannot be underestimated. The Referendum Council, established to consult with Aboriginal and Torres Strait Islander Peoples about their views on constitutional recognition in Australia, highlighted the importance of "truth-telling" in its 2017 final report. "Truth-telling" was one of three recommendations supported at each of the council's 18 dialogues, attended by a total of 1200 Aboriginal and Torres Strait Islander delegates around the country. As a delegate from Darwin stated: "Australia must acknowledge its history, its true history ... the massacres and the wars. If that were taught in schools, we might have one nation, where we are all together" (Reconciliation Australia 2018).

Arts-based methods and projects give the opportunity for participants to engage with the difficult histories of First Peoples in creative ways. 


\section{Symbolic Reconciliation and Evidence of Change in the Community}

Symbolic Reconciliation dialogues, are also an important part of a multi-dimensional approach to social justice. A further endorsement of the way change can be introduced was evidenced in the smoking ceremony preceding the handing over of the role of Head of School in Education and Social work at the University of Sydney in February of 2019. The incoming Head of School had asked for this ceremony to be conducted as a way of cleansing the role that she was taking over. Having tried unsuccessfully to extend the Aboriginal flag flying at the Faculty of Education and Social Work for several years, where it only flew once a year on Reconciliation Day, this was seen as a really important step forward. Aboriginal and Torres Strait Islanders are now being taken seriously as the flags of their respective nations fly daily.

\section{An Indigenous World-View or a Global Identity?}

Margaret Mead in much of her work relating to the notion of culture in American Society, used a range of ethnographies of Indigenous groups. According to Molloy (2008) much of Margaret Mead's early popular ethnographies asked the question: "(...) what was it in American culture between the wars that was articulated in Mead's early work in such a way as to secure it and her enduring place in the public imaginary?" (p. 1).

If Mead spoke to America, then just as surely America spoke to and through Mead. She goes on to note that her focus was not on Mead's anthropology of the various Indigenous groups she studied, but “(...) rather, I consider her de facto anthropology of America, a significant part of each of her early ethnographies, and the raison d'être for them all: "Who or what was this America?" is the question..." (ibid).

In relation to the Indigenous inhabitants of Australia and New Zealand, what sort of vision or world-view do they have? How are their realities any different to those of the white settlers in both of these countries? As a comparativist it is difficult not to ask these questions. The reality is that the two countries had completely different perspectives and responses to the arrival of white people. In New Zealand when faced with the threat of invasion by the white settlers, the Maori tended to fight. The Aboriginal and Torres Strait Islanders seemed more inclined to retreat more deeply into the Country and avoid conflict wherever possible (although there is evidence that stories Aboriginal and Torres Strait Islander resistance). This chapter cannot discuss these differences in detail, however, it is important to stress the thread that informs this chapter, in other words the notion of a global world-view. Did the original inhabitants of Australia and New Zealand have a conception of a world-view? 
Was the arrival of the white man something to be taken in their stride and even embraced?

Running through Molloy's commentary on Mead's life work on culture and identity is a sustained concentration on the self and its relation to the larger society. It is one of the arguments of this study that the self as represented is not just any individual but is in some sense "(...) both an American self and the self of America" (Molloy 2008, p. 1). Whether or not Indigenous Native American populations felt the same sense of belonging to this concept of self is unclear.

\section{Maori Perceptions on Global Identity}

This final section draws on the experience in Aotearoa New Zealand of Maori and Pacifica interactions with white settlers predominantly from Europe. The historical background of New Zealand is quite different to that of Australia. The settlement of New Zealand was for the most part, voluntary with many arriving to start a new life. Those early European settlers who originally arrived in Australia, were often convicts forcefully removed from the United Kingdom and sentenced to lengthy terms of settlement. In reality, most who arrived never returned to Europe.

The worldview of the Maori People is discussed in Te Putara, a self-proclaimed commentary and opinion paper for the Kumara ${ }^{6}$ Vine, the Maori equivalent of the grapevine. It is noted that the task of formulating a single Maori worldview is an ambitious undertaking given the diversity of viewpoints encouraged within Maori culture. The suggestion is made that a good starting point could be to define what it is to be Maori. Te Putatara (2019) suggests: "Being ethnically Maori and identifying as Maori would be the foundation of a Maori worldview, if there is one!" Rebecca Solnit asserts: "Given a choice between their worldview and the facts, it's always interesting how many people toss the facts" (as cited in Te Putatara 2019).

The figures provided by the 2013 Census in New Zealand found that there were 668,724 people of Maori descent in Aotearoa New Zealand of these 598,605 $(89.5 \%)$ identified as being Maori. About $87 \%$ live in the North Island and $13 \%$ in the South Island. There are a further 128,500 Maori (or approximately $17.6 \%$ of all Australasian Maori) living in Australia. According to the Putatara commentary, many Maori whanau ${ }^{7}$ in Australia and New Zealand now consider both countries as virtually the same country. The census figures show a merging of Maori and European in the context of religion and language where $98 \%$ of Maori identified as Christian and $100 \%$ speak English. Their worldviews merge although there is a noted discrepancy between those who say they know their whakapapa or lineage and those who do not.

\footnotetext{
${ }^{6} \mathrm{~A}$ Kumara is a sweet potato that was a key ingredient of the Maori diet before the arrival of white settlers in New Zealand. It has several varieties and is very tasty.

${ }^{7}$ Whanau is based on a specifically Maori and tribal worldview. It refers to the several layers of family connections. There is a physical, social and spiritual dimension to whanau.
} 
Education in an adapted Maori way plays a major role in shaping engagement of Assimilation across New Zealand. Te Aho Matua is the philosophical base for Kura Kaupapa or Māori education, for the teaching and learning of children. Te Aho Matua is presented in six parts, each part having a special focus on what, from a Māori point of view, is crucial in the education of children:

1. Te ira tangata: the physical and spiritual endowment of children and the importance of nurturing both in their education;

2. Te reo: principles by which this bilingual competence will be achieved;

3. Ng $\bar{a}$ iwi: principles important in the socialization of children;

4. Te ao: those aspects of the world that impact on the learning of children;

5. Áhuatanga ako: the principles of teaching practice that are of vital importance in the education of children;

6. Te tino uaratanga: the characteristics to be developed in children.

Maintaining a Maori language is a critical piece of the puzzle in providing a meaningful education for all members of New Zealand society. It is not unusual in New Zealand for pakeha or white European New Zealanders to learn Maori. Just over $20 \%$ of those who speak Maori, speak Te Reo Maori at a conversational level of fluency. It is possible for students to undertake all their primary schooling in Maori, however only about $2 \%$ are enrolled in Maori education. The use of language as a unifying force in a nation's development, rather than trying to force English as the official language has clearly paid dividends for New Zealand society at large. The use of Maori is evident throughout New Zealand with Radio and Television station personalities often using Maori forms of greeting. The pronunciation of place names in New Zealand still calls for a considerable amount of focus as to make a mistake may cause offence.

\section{Conclusion}

The Embedding Diversity research dialogues described can be replicated in a variety of different higher education contexts and applied in different learning environments including formal education and informal adult learning frameworks. Elders can be involved in shaping learning and the land embraced as a valuable learning partner to assist and reform understanding of First Peoples knowledge. The creative arts canvas mapping and story sharing projects strengthened relationships, awareness and understanding between the peoples who participated in them and can be iterated and re-iterated in schools, universities and through communities of practice. The creative arts research models described demonstrated the transformational possibilities of sharing Indigenous stories. Furthermore, it evidenced the value of embedding Aboriginal and Torres Strait Islander perspectives in comparative and international education (CIE) research, involving practitioners and students within Oceania and extending the dialogues to connect other oceans, islands and identities. 
We have described a shared story of two countries. ${ }^{8}$ We have storied some of the responses of their respective Indigenous inhabitants to questions facing all nations in their quest for both survival and acceptance in a rapidly globalizing world. The questions are really concerned with the notion of change and adaptation of, what has always been, a contested space. The questions pose reform, recognition and change to enable Indigenous participation. The questions probe the need for the democratization of learning, teaching and research spaces through the inclusion of Indigenous perspectives.

The chapter has created a dilly bag. ${ }^{9}$ It is a dilly bag of questions that demand to be answered in ways that include, celebrate and involve First Peoples, their histories, stories and creativities. Some of these questions include: How does Oceania function as an island of knowing? How do we carve out space for Oceanic ways of knowing, thinking and being through multicultural perspectives? How can we engage in Global Reconciliation dialogues that honor Indigenous knowledge and people? There will be new ways and old ways (Moore and Birrell 2011) to listen, work with and adapt while opening different voices to citizenship.

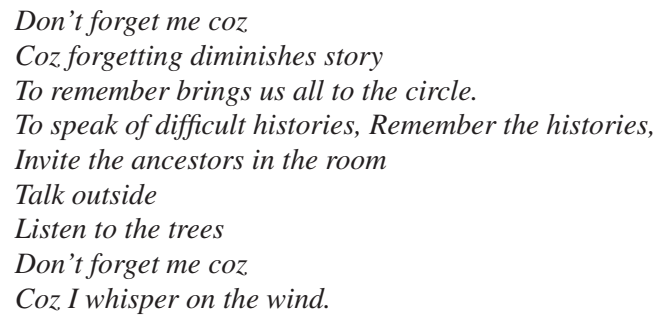

Acknowledgment The authors acknowledge and pay their respects to the traditional owners of the Land on which they work, live, learn and travel through. They pay respect to Elders past, present and emerging. Always was, always will be Aboriginal lands.

\section{References}

Ahluwalia, P., Atkinson, S., Bishop, P., Christie, P., Hattam, R., \& Matthews, J. (Eds.). (2012). Reconciliation and pedagogy. London: Routledge.

Burney, L. (2000). Not just a challenge, an opportunity. In M. Grattan (Ed.), Reconciliation: Essays on Australian reconciliation. Melbourne: Bookman Press.

Chemi, T., \& Du, X. (2018). Tracing arts-based methods in higher education. In T. Chemi \& X. Du (Eds.), Arts-based methods and organizational learning (pp. 1-18). Cham: Palgrave Macmillan.

\footnotetext{
${ }^{8}$ The chapter also drew upon the Chamorro people from the Mariana Islands of Guam and the Kanak (French spelling till 1984, Canaque) of New Caledonia.

${ }^{9}$ The dilly bag is a traditional Australian Aboriginal bag, woven from the fibres of plants and used for a variety of food transportation and preparation purposes and in some communities was as a holder for personal or tribal artefacts.
} 
Martin, K. L. (2008, April 14). Aboriginal worldview, knowledge and relatedness theory: A framework for pedagogy and praxis and the teaching - Learning interface with Aboriginal students. Canberra: School of Education, Southern Cross University (Lismore) IATSIS Seminar.

May, S., \& Sleeter, C. E. (Eds.). (2010). Critical multiculturalism: Theory and praxis. New York: Routledge.

Moll, L., Amanti, C., Neff, D., \& Gonzalez, N. (1992). Funds of knowledge for teaching: Using a qualitative approach to connect homes and classrooms. Theory Into Practice, 31(2), 132-141.

Molloy, M. A. (2008). On creating a usable culture: Margaret Mead and the emergence of American cosmopolitanism. Honolulu: University of Hawaii Press.

Mooney, J., \& Moore, S. J. (2013). Shifting the emphasis: Embedding and reflecting on introducing aboriginal studies and perspectives diversity. In R. G. Craven \& J. Mooney (Eds.), Seeding success in indigenous Australian Higher Education (Diversity in higher education, volume 14) (pp. 301-318). Bingley: Emerald Group Publishing Limited.

Moore, S. J., \& Birrell, C. (2011). New ways, old ways. In N. Bagnall \& E. Cassity (Eds.), Education and belonging (pp. 111-122). New York: Nova Science.

Reconciliation Australia. (2018). Truth-telling Central to Reconciliation Process|Reconciliation Australia. Retrieved from https://www.reconciliation.org.au/ truth-telling-central-to-reconciliation-process/

Riley, L., Howard-Wagner, D., \& Mooney, J. (2015). Kinship online: Engaging 'cultural praxis' in a teaching and learning framework for cultural competence. The Australian Journal of Indigenous Education, 44(1), 70-84. https://doi.org/10.1017/jie.2015.13.

Sanga, K. (2017). Leadership development through friendship and storytelling. In U. Lumā Vaai \& A. Casamira (Eds.), Relational hermaneutics: Decolonizing the mindset and the Pacific Itulagi (pp. 101-113). Suva: University of the South Pacific Press \& Pacific Theological College.

Simpson, A., \& Moore, S. J. (2008). Uncomfortable learning: Connecting to country. Synergy, 28, 4-9.

Te Putatara, Commentary and Opinion for the Kumara Vine. (2019). The Maori worldview and Maori policy. Retrieved from https://www.reconciliation.org.au/ truth-telling-central-to-reconciliation-process/

Vélez-Ibáñez, C., \& Greenberg, J. (1992). Formation and transformation of funds of knowledge among US-Mexican households. Anthropology \& Education Quarterly, 23 (4), 313-335.

Open Access This chapter is distributed under the terms of the Creative Commons Attribution 4.0 International License (http://creativecommons.org/licenses/by/4.0/), which permits use, duplication, adaptation, distribution and reproduction in any medium or format, as long as you give appropriate credit to the original author(s) and the source, a link is provided to the Creative Commons licence and any changes made are indicated.

The images or other third party material in this chapter are included in the work's Creative Commons licence, unless otherwise indicated in the credit line; If such material is not included in the work's Creative Commons licence and the respective action is not permitted by, users will need to obtain permission from the license holder to duplicate, adapt or reproduce the material.

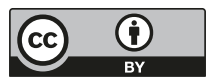

